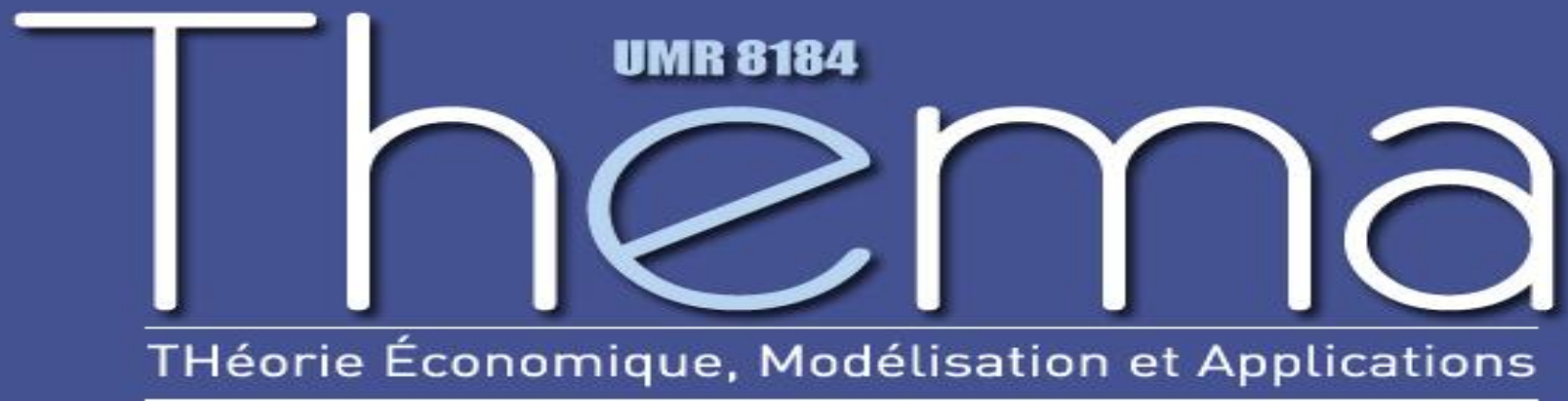

Thema Working Paper $\mathrm{n}^{\circ}$ 2011-07

Université de Cergy Pontoise, France

Optimal Commodity Taxation and Redistribution within Households

Olivier Bargain

Olivier Donni

March, 2011 


\title{
Optimal Commodity Taxation and Redistribution within Households*
}

\author{
Olivier Bargain ${ }^{\dagger} \quad$ Olivier Donni ${ }^{\ddagger}$
}

March 2011

\begin{abstract}
Using a collective model of consumption, we characterize optimal commodity taxes aimed at targeting specific individuals within the household. The main message is that distortionary indirect taxation can circumvent the agency problem of the household. Essentially, taxation should discourage less the consumption of a certain group of goods: those for which the slope of the Engel curves is larger for the targeted person.
\end{abstract}

Key Words : optimal commodity taxation, targeting, intrahousehold distribution.

Classification JEL : D13, D31, D63, H21, H31

${ }^{*}$ Correspondence: Olivier Bargain, UCD, Newman Building, Dublin 4, Ireland. Phone: +35317168357.

Email: olivier.bargain@ucd.ie

${ }^{\dagger}$ University College Dublin, IZA and CHILD

${ }^{\ddagger}$ Université de Cergy-Pontoise, THEMA and IZA 


\section{Introduction}

As is well known, commodity taxation can be used as a redistributive device. In optimal taxation, Diamond (1975) shows that commodities consumed by the targeted group should be less discouraged by the tax system. Related approaches are interested in the role of (marginal) commodity taxation in improving social welfare (Ahmad and Stern, 1984) or reducing poverty (Makdissi and Wodon, 2002). In the same way, it may be possible to target specific, possibly disadvantaged, individuals within households (e.g., children, women) by choosing optimally the tax rates of some commodities. Despite evidence that deprivation affects particular individuals within families (e.g., Haddad and Kanbur, 1990), there is little theoretical foundation of the effect of price distortions on the welfare of individuals within households.

There exists nonetheless a growing literature on the optimal or marginal taxation of multiperson households (see the general discussion in Pollak, 2005). In particular, the model of Apps and Rees (1988), concerned with labor supply decisions, focuses on optimal (linear) income taxation. Balestrino (2004) makes use of a non-cooperative household model where public goods (children) generate inefficiencies within the household. Cigno et al. (2003) examine policies that aim to improve child welfare while Bargain and Donni (2011) compare the effect of price subsidies and cash transfers on child welfare and child poverty (following the literature on targeting, cf., Besley and Kanbur, 1988). Cremer and Pestieau (2001) study the optimal non-linear taxation of bequest using a model with altruistic parents. A few authors also study marginal tax reforms in a collective framework (Brett, 1988, and with extension to domestic production and labor supply, Allgood, 2009). More generally, the recent paper of Kleven et al. (2009) on the optimal taxation of couples focuses on across-family redistribution, yet provides ample motivations to study the effect of redistributive taxation within families by use of collective models.

This paper aims to bring the literature forward by studying the intra-household redistribution operated via optimal commodity taxation. Using a multi-person household model, 
which corresponds to the collective model or to prior versions where Pareto weights are constant, we characterize the optimal commodity taxes or subsidies that favor specific individuals in the household in a way which possibly departs from the household's own redistributive rules (i.e., there is dissonance, in the terminology of Apps and Rees, 1988). Essentially, we show that the consumption of the goods for which the slope of the Engel curves is larger for the targeted person should be less discouraged. This conclusion contrasts with that of Diamond (1975). We then examine the robustness of this result when alternative instruments are available, notably instruments that allow governments to collect tax revenue without distortion (lump-sum taxation) or to directly affect individual resource shares in the household. Given that the two latter types of policies are rarely available, our results suggest using distortionary indirect taxation to circumvent the agency problem of the household. Since children, men and women tend to consume different products/services, there is ample scope for the implementation of redistributive policies of that type.

\section{The Household Model}

\subsection{The Model and its Comparative Statics}

In this section, we consider a two-person household whereby each member $i(i=1,2)$ is characterized by a monotonic, concave, and twice differentiable utility function $u_{i}\left(\mathbf{x}_{i}\right)$ which depends on a $n$-vector of private goods $\mathbf{x}_{i}$. The $n$-vector of prices is denoted by p and household income by $Y$. To specify household behavior, we assume the following.

A1. The outcome of the decision process is assumed to be Pareto-efficient. The household optimization program can thus be written:

$$
\max _{\mathbf{x}_{1}, \mathbf{x}_{2}} \mu^{*}(\mathbf{p}, Y) \cdot u_{1}\left(\mathbf{x}_{1}\right)+\left(1-\mu^{*}(\mathbf{p}, Y)\right) \cdot u_{2}\left(\mathbf{x}_{2}\right) \quad \text { s.t. } \quad\left(\mathbf{x}_{1}+\mathbf{x}_{2}\right)^{\prime} \mathbf{p} \leq Y .
$$

The weight $\mu^{*}$ determines the location of the household along the Pareto frontier; it is 
supposed to be differentiable with respect to prices and income. Several comments must be made. Firstly, this framework is completely standard. In particular, the separability in the household welfare function is accepted by the majority of economists, even if not without reservations (Gronau, 1988). Secondly, the generalization to more than two household members is feasible but results are more difficult to interpret. The presence of a disadvantaged versus an advantaged person in the household is enough for our argument. Thirdly, this setting is very general. For instance, the household may comprise a single decision maker (the parent, 1) and a powerless person (the child, 2), so that the household welfare function is simply the objective function of the benevolent parent while Pareto weights reflect her level of altruism vis-à-vis the child (Becker, 1991, Bargain and Donni, 2011). ${ }^{1}$ The model may also describe the behavior of two adults whose relative bargaining positions are represented by the Pareto weights. In that case, prices and income are likely to affect adults' bargaining position, as in the model of Apps and Rees (1988) or the collective model of Chiappori (1988). These two adults are typically the spouses, but they may also correspond to the head of household and another decision maker like an older child (see Dauphin et al., 2011).

The first order conditions of the optimization program $(\mathrm{P})$ are:

$$
\frac{\partial u_{i}}{\partial \mathbf{x}_{i}}=\eta_{i} \mathbf{p}
$$

for $i=1,2$, where $\eta_{i}=\lambda^{*} / \mu_{i}^{*}$ is the marginal utility of wealth for member $i$, with $\lambda^{*}$ the Lagrange multiplier associated to the budget constraint, $\mu_{1}^{*}=\mu^{*}$ and $\mu_{2}^{*}=1-\mu^{*}$. Solving first order conditions with the budget constraint yields the vectors of individual and household demands:

$$
\mathbf{x}_{i}=\mathbf{x}_{i}(\mathbf{p}, Y), \quad i=1,2 .
$$

\footnotetext{
${ }^{1}$ With this interpretation, it may be acceptable to assume that Pareto weights are independent of prices and income, which is compatible with early representations of multi-person households such as the Rotten Kid model (Becker 1974, 1991) or the Consensus model (Samuelson, 1956). See Chiappori and Donni (2011) for a survey of the multi-person household literature.
} 
The optimization program $(\mathrm{P})$ is separable so that the decision process can be decentralized: total income is first divided between members according to a sharing rule, then individual programs are solved as if each individual maximized her own utility subject to her own share of income. Let $v_{i}\left(\mathbf{p}, \phi_{i}\right)$ be member $i$ 's indirect utility function where $\phi_{i}$ is her share of income. The latter is the solution to:

$$
\max _{\phi_{1}, \phi_{2}} \mu^{*}(\mathbf{p}, Y) \cdot v_{1}\left(\mathbf{p}, \phi_{1}\right)+\left(1-\mu^{*}(\mathbf{p}, Y)\right) \cdot v_{2}\left(\mathbf{p}, \phi_{2}\right) \quad \text { s.t. } \quad \phi_{1}+\phi_{2}=Y .
$$

The first order condition of this program is:

$$
\mu_{1}^{*} \frac{\partial v_{1}}{\partial \phi_{1}}-\mu_{2}^{*} \frac{\partial v_{2}}{\partial \phi_{2}}=0
$$

and determines the intra-household sharing of income. Once this is done, individual programmes can be written:

$$
\max _{\mathbf{x}_{i}} u_{i}\left(\mathbf{x}_{i}\right) \quad \text { subject to } \quad \mathbf{p}^{\prime} \mathbf{x}_{i} \leq \phi_{i}(\mathbf{p}, Y)
$$

Hence, individual demands are characterized by the following structure:

$$
\mathbf{x}_{i}=\chi_{i}\left(\mathbf{p}, \phi_{i}\right)
$$

where $\boldsymbol{\chi}_{i}(\cdot)$ is a traditional Marshallian demand function. To simplify notation, let $\phi=\phi_{1}$ and $Y-\phi=\phi_{2}$, where $\phi(\mathbf{p}, Y)$ is the so-called sharing rule.

To determine how the intra-household distribution of resources is affected by taxation, we calculate the derivatives of the sharing rule with respect to income and prices. First, we differentiate the condition (1) with respect to $Y$ and, after some manipulations, we obtain:

$$
\frac{\partial \phi}{\partial Y}=-\frac{\eta_{2}^{\prime} / \eta_{2}}{\theta}+M_{Y}
$$

with

$$
\theta=-\left(\frac{\eta_{1}^{\prime}}{\eta_{1}}+\frac{\eta_{2}^{\prime}}{\eta_{2}}\right)>0 \quad \text { and } \quad M_{Y}=\frac{1}{\theta}\left(\frac{\partial \log \mu_{1}^{*}}{\partial Y}-\frac{\partial \log \mu_{2}^{*}}{\partial Y}\right),
$$

where $\eta_{i}=\partial v_{i} / \partial \phi_{i}$ and $\eta_{i}^{\prime}=\partial^{2} v_{i} / \partial \phi_{i}^{2}$. The first term on the right-hand-side of expression (3) tells us that, when bargaining weights are kept constant, an increase in income should 
benefit both members, but the share is larger for the individual located on the least curved portion of her utility function. The second term represents the effect of bargaining weights: if the (log-)weight of member 1 (relatively to that of member 2 ) increases with income, then her share of income will increase as well. Bargain and Donni (2011) show that the term $\theta$ corresponds to the derivative of the household marginal rate of substitution, computed at the equilibrium, between the two persons' allocations (a measure of the convexity of household preferences regarding allocations $\phi_{1}$ and $\phi_{2}$ ). It tends to zero when the substitution between members' income share in problem $(\overline{\mathrm{P}})$ is perfect (i.e., indifference curves are straight lines) and equal to infinity when the complementarity is perfect (i.e., indifference curves are right-angled lines). The term $\theta$ is therefore referred to as the index of complementarity henceforth.

We can now compute the effect of prices on member 1's income share. First, from Roy's identity, we have:

$$
\frac{\partial v_{i}}{\partial \mathbf{p}}=-\eta_{i} \mathbf{x}_{i}, \quad \frac{\partial^{2} v_{i}}{\partial \mathbf{p} \partial \phi_{i}}=-\eta_{i}^{\prime} \mathbf{x}_{i}-\eta_{i} \frac{\partial \boldsymbol{\chi}_{i}^{j}}{\partial \phi_{i}}
$$

Introducing these expressions in the derivative of (1) with respect to $\mathbf{p}$, and using (3), leads to:

$$
\frac{\partial \phi}{\partial \mathbf{p}}=\left(\left(\mathbf{x}_{1}-\mathbf{R}\right)-\frac{\partial \phi}{\partial Y} \mathbf{x}\right)-\left(M_{\mathbf{p}}-\mathbf{x} M_{Y}\right)
$$

where $\mathbf{x}=\mathbf{x}_{1}+\mathbf{x}_{2}$ and

$$
\mathbf{R}=\frac{1}{\theta}\left(\frac{\partial \boldsymbol{\chi}_{1}}{\partial \phi_{1}}-\frac{\partial \boldsymbol{\chi}_{2}}{\partial \phi_{2}}\right) \quad \text { and } \quad M_{\mathbf{p}}=\frac{1}{\theta}\left(\frac{\partial \log \mu_{1}^{*}}{\partial \mathbf{p}}-\frac{\partial \log \mu_{2}^{*}}{\partial \mathbf{p}}\right)
$$

The first term (bracket) on the right hand side of expression (4) is the price effect when bargaining weights remain constant while the second term represents the redistribution due to the effect of prices on bargaining weights. The latter include the direct effect of prices on weights and an income effect. The former has two components. First, Bargain and Donni (2011) show that the term $\left(\mathbf{x}_{1}-\mathbf{R}\right)$ is the change in member 1's share of income resulting from a simultaneous variation in prices and in income that keeps total household welfare unchanged. Second, the term $(\partial \phi / \partial Y) \mathbf{x}$ is a 'conventional' income effect: person 
1 's endowment decreases because the real income of the household is reduced by the rise in the commodity price.

\subsection{Elements of Duality Theory.}

Some elements of duality theory will be necessary to interpret the optimal tax rates we shall obtain. Let $e_{i}\left(\mathbf{p}, u_{i}\right)$ be the expenditure function of member $i$ (dual to the indirect utility function $\left.v_{i}\left(\mathbf{p}, \phi_{i}\right)\right)$. The 'household' expenditure function $e\left(\mathbf{p}, u_{1}, u_{2}\right)$ is then defined as follows:

$$
e\left(\mathbf{p}, u_{1}, u_{2}\right)=e_{1}\left(\mathbf{p}, u_{1}\right)+e_{2}\left(\mathbf{p}, u_{2}\right)
$$

This function represents the minimum level of expenditure which is required for household members to attain levels of utility $\left(u_{1}, u_{2}\right)$ when prices are equal to $\mathbf{p} .^{2}$ The Envelop Theorem then gives:

$$
\begin{aligned}
\frac{\partial e}{\partial \mathbf{p}}\left(\mathbf{p}, u_{1}, u_{2}\right) & =\boldsymbol{\chi}_{1}^{c}\left(\mathbf{p}, u_{1}\right)+\boldsymbol{\chi}_{2}^{c}\left(\mathbf{p}, u_{2}\right) \\
& =\boldsymbol{\chi}^{c}\left(\mathbf{p}, u_{1}, u_{2}\right)
\end{aligned}
$$

where $\boldsymbol{\chi}_{i}^{c}(\cdot)$ denotes the vector of member $i$ 's compensated demand functions, $\chi^{c}(\cdot)$ the vector of household compensated demand functions (that is, the minimum level of goods necessary to attain levels of utility $\left(u_{1}, u_{2}\right)$ for prices equal to $\mathbf{p}$, and

$$
\frac{\partial^{2} e}{\partial \mathbf{p} \partial \mathbf{p}^{\prime}}\left(\mathbf{p}, u_{1}, u_{2}\right)=\frac{\partial \boldsymbol{\chi}^{c}}{\partial \mathbf{p}^{\prime}}\left(\mathbf{p}, u_{1}, u_{2}\right)=\mathbf{S}
$$

where $\mathbf{S}$ is a symmetric, semi-definite negative matrix. Let us define $\overline{\mathbf{S}}$ as the pseudoSlutsky matrix of the household:

$$
\overline{\mathbf{S}}=\frac{\partial \mathbf{x}}{\partial \mathbf{p}^{\prime}}+\frac{\partial \mathbf{x}}{\partial Y} \mathbf{x}^{\prime}
$$

\footnotetext{
${ }^{2}$ Other representations of the 'collective' expenditure function can be found in the literature. See Browning and Chiappori (1998) for instance.
} 
In the appendix, it is shown that

$$
\overline{\mathbf{S}}=\left(\mathbf{S}-\theta \mathbf{R} \mathbf{R}^{\prime}\right)+\theta \mathbf{R}\left(M_{\mathbf{p}}-\mathbf{x} M_{Y}\right)^{\prime}
$$

On the right-hand-side, the first matrix in brackets is the 'unitary' substitution effect under the assumption that bargaining weights are constant. The second matrix, of rank one, corresponds to the move along the Pareto frontier due to changes in bargaining weights (Browning and Chiappori, 1998; Donni, 2006). Importantly, if bargaining weights are constant, the second matrix is equal to zero so that:

$$
\overline{\mathbf{S}}=\left(\mathbf{S}-\theta \mathbf{R} \mathbf{R}^{\prime}\right)
$$

is a symmetric, semi-definite negative matrix.

\section{Optimal Commodity Taxation}

We suppose that the household is representative and the government may use excise taxes on the goods $1, \ldots, N$ to raise a certain amount of required revenue $B$. We consider two cases: (a) constant bargaining weights, and (b) variable bargaining weights.

\subsection{Constant Bargaining Weights}

If bargaining weights are interpreted as altruistic terms (caring, in the sense of Becker, 1991), for instance when 2 is a powerless household member, it is not unreasonable to suppose that they do not depend on prices and income. Formally we suppose the following:

A2. The bargaining weights are constant, that is, $\mu_{i}^{*}(\mathbf{p}, Y)=\bar{\mu}_{i}^{*}$, for $i=1,2$.

This assumption simplifies the whole reasoning. The social planner has a set of tax rates $\mathbf{t}$ as instruments and desire to maximize a social welfare function as follows:

$$
\max _{\mathbf{t}} \mu_{1} v_{1}(\mathbf{q}+\mathbf{t}, \phi)+\mu_{2} v_{2}(\mathbf{q}+\mathbf{t}, Y-\phi)
$$


with $\mu_{1}+\mu_{2}=1$, subject to a revenue constraint

$$
\left(\mathbf{x}_{1}+\mathbf{x}_{2}\right)^{\prime} \mathbf{t}=B
$$

where $\mathbf{q}$ is the set of pre-tax commodity prices (and $\mathbf{q}=\mathbf{p}-\mathbf{t}$ ), $\mu_{i}$ is the social welfare weight on member $i$ in the planner's function and $B$ the revenue target. If the social weights $\mu_{i}$ coincide with the bargaining weights $\mu_{i}^{*}$ that characterize the decision process in the household, the traditional Ramsey rule applies and the derivation of the optimal tax rates is straightforward. However, this will not necessarily be the case, i.e., there may be dissonance between the preferences of the household and those of the social planner (Apps and Rees, 1988). We shall focus on this very case for the intra-household redistributive is important. The first order conditions are:

$$
\frac{\mu_{1}}{\lambda}\left(\frac{\partial v_{1}}{\partial \mathbf{p}^{\prime}}+\frac{\partial v_{1}}{\partial \phi} \frac{\partial \phi}{\partial \mathbf{p}^{\prime}}\right)+\frac{\mu_{2}}{\lambda}\left(\frac{\partial v_{2}}{\partial \mathbf{p}^{\prime}}-\frac{\partial v_{2}}{\partial \phi} \frac{\partial \phi}{\partial \mathbf{p}^{\prime}}\right)=-\mathbf{x}^{\prime}-\mathbf{t}^{\prime} \frac{\partial \mathbf{x}}{\partial \mathbf{p}^{\prime}},
$$

where $\lambda^{-1}$ is the price of one unit of social welfare in terms of fiscal revenue. Since

$$
\frac{\partial v_{i}}{\partial \phi_{i}}=\frac{\lambda^{*}}{\mu_{i}^{*}}, \quad \frac{\partial v_{i}}{\partial \mathbf{p}}=-\frac{\lambda^{*}}{\mu_{i}^{*}} \mathbf{x}_{i}
$$

it can be rewritten as:

$$
\beta_{1}\left(\mathbf{x}_{1}^{\prime}-\frac{\partial \phi_{1}}{\partial \mathbf{p}^{\prime}}\right)+\beta_{2}\left(\mathbf{x}_{2}^{\prime}-\frac{\partial \phi_{2}}{\partial \mathbf{p}^{\prime}}\right)=\mathbf{x}^{\prime}+\mathbf{t}^{\prime} \frac{\partial \mathbf{x}}{\partial \mathbf{p}^{\prime}}
$$

where

$$
\beta_{i}=\frac{\lambda^{*} / \lambda}{\mu_{i}^{*} / \mu_{i}}, \quad i=1,2
$$

The term $\lambda / \lambda^{*}$, the price of one unit of social welfare in terms of household welfare, is common to both $\beta$ coefficients. The ratio of social weight and household weight $\mu_{i} / \mu_{i}^{*}$ reflects the dissonance. Then $\beta_{1}>\beta_{2}$ if social preferences are relatively more favorable to member 1 than household preferences are.

The tax policy can be broken down into an efficiency motive and a redistributive motive. To show this, we use the Slutsky condition (7) and the derivative of the sharing rule (4), and obtain:

$$
\overline{\mathbf{S}} \mathbf{t}=\alpha \mathbf{x}+\left(\beta_{1}-\beta_{2}\right) \mathbf{R}
$$


with

$$
\alpha=\left(\mathbf{t}^{\prime} \frac{\partial \mathbf{x}}{\partial Y}+\frac{\partial \phi_{1}}{\partial Y} \beta_{1}+\frac{\partial \phi_{2}}{\partial Y} \beta_{2}-1\right) .
$$

If $\mathbf{p}^{\prime} \mathbf{x}=0$, the equations are linearly dependent, so that the tax rate for one good must be arbitrarily fixed to zero. ${ }^{3}$ Then, as it is usual, the left hand side of this expression can be interpreted as an approximation of the total variation in compensated demand for goods resulting from the introduction of the tax system from an initial no-tax situation. The first term on the right hand side is similar to the efficiency motive that can be found in the usual Ramsey rule. The second term represents the redistributive motive which vanishes in case of non-dissonance (that is, when $\beta_{1}=\beta_{2}$ ). Consequently, in contrast to what happens in traditional theory, the consumption of certain goods may be discouraged or encouraged by the tax system. Suppose that $\beta_{1}>\beta_{2}$. Then, the consumption of goods for which the Engel slope of member 1 is larger than that of member 2 will be discouraged and the consumption of goods for which this inequality is inverted will be encouraged. The amplitude of the redistributive motive increases when the index of complementarity $\theta$ decreases.

The redistributive motive makes the extended Ramsey rule different from the traditional Ramsey rule. The former is actually reduced to the latter if one of the following conditions is satisfied: (a) there is no dissonance between household and social preferences, (b) the demand functions possesses linear Engel curves with common slopes across individuals, or (c) the index of complementarity tends to infinity. This extended Ramsey rule also contrasts with the optimal rule derived by Diamond (1975) for an economy with heterogeneous agents. The latter rule states that the goods which are essentially consumed by the targeted groups, independently of the slope of the Engel curves, should be encouraged or less discouraged.

If $\mathbf{p}^{\prime} \mathbf{x} \neq \mathbf{0}$ and all the goods are taxable, the optimal rule can be simplified. Indeed,

\footnotetext{
${ }^{3}$ To prove this, it is sufficient to pre-multiply expression (9) by $\mathbf{p}^{\prime}$ and note that the left-hand side and the right-hand side vanish.
} 
pre-multiplying expression (9) by $\mathbf{p}^{\prime}$ and using the homogeneity of demand functions demonstrate that $\alpha=0$. The optimal tax rule then becomes:

$$
\overline{\mathbf{S}} \mathbf{t}=\left(\beta_{1}-\beta_{2}\right) \mathbf{R}
$$

In particular, a proportional taxation is not optimal unless the right-hand-side of expression (10) is equal to zero. That is, a proportional tax is optimal if the demand functions possesses linear Engel curves with common slopes across individuals - this result is reminiscent of Deaton (1976) - or if there is no dissonance between the household redistribution scheme and the social planner's redistributive objectives.

The interpretation of the optimality rule becomes clearer if commodity $j$ is exclusively consumed, for example, by member 1 . In that case, the rule can be written:

$$
\frac{\sum_{k=1}^{n} \bar{s}_{j k} t_{k}}{x^{j}}=\alpha+\zeta \varepsilon_{j}
$$

where $\bar{s}_{j k}$ is a generic element of $\overline{\mathbf{S}}$, and

$$
\zeta=-\frac{\beta_{1}-\beta_{2}}{Y\left(\eta_{2}^{\prime} / \eta_{2}\right)}
$$

is measure of the redistributive capacity of the tax system, and

$$
\varepsilon_{j}=\frac{Y}{x^{j}}\left(\frac{\partial \chi_{1}^{j}}{\partial \phi_{1}} \frac{\partial \phi_{1}}{\partial Y}\right)
$$

is the income elasticity of good $j$; the left-hand-side is the 'index of discouragement' in Mirrless (1976)'s terminology. The level of taxation of an exclusive good is thus related to the elasticity of its demand with respect to income. In particular, if $\zeta>0$, i.e., social preferences are relatively more favorable to member 1 than household preferences are, and if the exclusive good $j$ is normal, then its consumption will be relatively encouraged (or less discouraged) by the tax system. 


\subsection{Varying Pareto Weights}

We now extend the previous framework to the case where Pareto weights depend on post-tax prices and income, i.e., $\mu^{*}=\mu^{*}(\mathbf{p}, Y) .{ }^{4}$ In this more general case, the program (P) corresponds to a collective model with private consumption (Chiappori, 1988). After some manipulations, the optimal tax rule is now:

$$
\left(\mathbf{S}-\theta \mathbf{R} \mathbf{R}^{\prime}\right) \mathbf{t}=\alpha \mathbf{x}+\left(\beta_{1}-\beta_{2}\right) \mathbf{R}+\left[\left(\beta_{1}-\beta_{2}\right)+\gamma\right]\left(M_{\mathbf{p}}-\mathbf{x} M_{Y}\right)
$$

where $\gamma=\theta \mathbf{R}^{\prime} \mathbf{t}$. The left-hand-side is defined by equation (8); it can again be interpreted as the total variation of the compensated demand functions (on the condition that the latter are defined as the demand functions conditional on the level of total utility and on bargaining weights). The first and second terms on the right-hand-side have a similar interpretation to that in (9). The third term necessary reflects the additional redistributive effects from commodity taxation induced by changes in the bargaining weights. To interpret it better, suppose that an increase in the price of good $j$ is favorable to the weight of member 1 (relative to the weight of member 2). That means that $M_{\mathbf{p}}-\mathbf{x} M_{Y}$ is positive. If the social planner is relatively more favorable to member 1 , i.e., $\beta_{1}-\beta_{2}>0$, then, all other things being the same, the tax system must encourage the consumption of good $j$. However, the tax system also creates distortion at the household level due to variations in the bargaining weights. In particular, the gain or loss in tax revenue for the government when one dollar is transferred from member 2 to member 1 via the sharing rule is represented by $\gamma$. If, for instance, $\gamma>0$, the empowerment of member 1 increases tax revenue and the consumption of good $j$ must be all the more encouraged. If $\gamma<0$, encouraging the consumption of good $j$ has a cost in terms of tax revenue.

The sign of $M_{\mathbf{p}}-\mathbf{x} M_{Y}$ can be positive or negative so that it is difficult to draw clearcut conclusions. To restrict the dependence of bargaining weights on prices, however, we follow Browning and Chiappori (1998) and impose some additional structure:

\footnotetext{
${ }^{4}$ Alternatively, we can also suppose that tax rates enter bargaining weights as specific arguments, i.e., $\mu^{*}=\mu^{*}(\mathbf{p}, \mathbf{t}, y)$. However, it is difficult to draw strong conclusions at this level of generality.
} 
A3. The bargaining weights depend on income deflated by a linear homogeneous price index $\pi(\mathbf{p})$, that is,

$$
\mu_{i}^{*}(\mathbf{p}, Y)=m_{i}^{*}\left(\frac{Y}{\pi(\mathbf{p})}\right)
$$

In other words, the bargaining weights are affected by prices in as much as the prices influence the real income of the household. This reflects the idea that prices are likely to have a moderate impact on bargaining weights. ${ }^{5}$ Then,

$$
M_{\mathbf{p}}-\mathbf{x} M_{Y}=\nu \frac{\partial \pi}{\partial \mathbf{p}}
$$

where

$$
\nu=-\frac{Y}{\theta \pi^{2}} \cdot\left(\frac{\partial \log m_{1}^{*}}{\partial(Y / \pi(\mathbf{p}))}-\frac{\partial \log m_{2}^{*}}{\partial(Y / \pi(\mathbf{p}))}\right) .
$$

The optimal rule (11) then becomes:

$$
\left(\mathbf{S}-\theta \mathbf{R} \mathbf{R}^{\prime}\right) \mathbf{t}=\alpha \mathbf{x}+\left(\beta_{1}-\beta_{2}\right) \mathbf{R}+\left[\left(\beta_{1}-\beta_{2}\right)+\gamma\right] \nu \frac{\partial \pi}{\partial \mathbf{p}}
$$

In addition, some empirical evidence (Haddad and Kanbur, 1994) seems to indicate that resources are more equally distributed in high-income households than in low-income households. In that case, a larger $Y$ implies a larger $m_{1}^{*} / m_{2}^{*}$, if we assume that 1 is the disadvantaged person, and $\nu$ is therefore negative. Then, if the government is supposed to be favorable to a more equal distribution of resources within the household, the sign of $\nu$ must be opposed to that of $\left(\beta_{1}-\beta_{2}\right)$, the latter being positive. Neglecting $\gamma$, this implies that the last term on the right-hand-side of expression (12) is negative and proportional to $\partial \pi / \partial \mathbf{p}$. Intuitively, if the value of $\partial \pi / \partial p_{j}$ for some good $j$ is particularly large and positive, the increase in the tax rate on this very good will have a significant effect on the household real income and, according to the empirical evidence mentioned above, on the bargaining position of member 1 (relatively to that of member 2) in the household. This is why the tax placed on good $j$ will tend to be large.

\footnotetext{
${ }^{5}$ One exception is wage rates that are known to influence bargaining positions in the household.
} 
More can be said if we suppose that $\pi(\mathbf{p})$ is a true cost of living index, defined at the after-tax reference utility, that is,

$$
\pi(\mathbf{p})=\frac{e\left(\mathbf{p}, u_{1}^{*}, u_{2}^{*}\right)}{Y}
$$

where $\left(u_{1}^{*}, u_{2}^{*}\right)$ are the utility levels attained by members 1 and 2 after taxes. Then $\partial \pi / \partial \mathbf{p}=\mathbf{x} / Y$, and the optimal rule becomes

$$
\left(\mathbf{S}-\theta \mathbf{R} \mathbf{R}^{\prime}\right) \mathbf{t}=\bar{\alpha} \mathbf{x}+\left(\beta_{1}-\beta_{2}\right) \mathbf{R}
$$

where $\bar{\alpha}=\alpha+\left[\left(\beta_{1}-\beta_{2}\right)+\gamma\right] \nu / Y$. In this cas, the optimal rule is analogous to that when bargaining weights are constant. That is, this rule is valid as an approximation if the prices affect bargaining weights in as much as real income is affected.

\section{Additional Instruments}

In this section, we investigate the combination of several policy instruments.

\subsection{Lump-sum taxation}

Firstly, suppose that the planner can use an additional source of tax collection, namely lump-sum taxation. Assuming constant Pareto weight for simplicity, and denoting the level $T$ of such tax collected at the household level, the revenue constraint becomes:

$$
\left(\mathbf{x}_{1}+\mathbf{x}_{2}\right)^{\prime} \mathbf{t}+T=B
$$

Using previous definitions, the first order condition (with respect to $T$ ) is written:

$$
\frac{\mu_{1}}{\lambda} \frac{\partial v_{1}}{\partial Y}+\frac{\mu_{2}}{\lambda} \frac{\partial v_{2}}{\partial Y}=-1-\mathbf{t}^{\prime} \frac{\partial \mathbf{x}}{\partial Y}
$$

because $T$ has only an income effect, or

$$
\beta_{1} \frac{\partial \phi_{1}}{\partial Y}+\beta_{2} \frac{\partial \phi_{2}}{\partial Y}=1-\mathbf{t}^{\prime} \frac{\partial \mathbf{x}}{\partial Y}
$$


which means that $\alpha=0$. Consequently, in the presence of lump sum taxation, the motive of taxation in rules (10) or (12) is purely redistributive. In particular, if there is nondissonance, i.e., $\beta_{1}=\beta_{2}$, the tax rates should be set to zero Indeed, it is easy to show that the optimal rule holds when $\mathbf{t}=\mathbf{0}$.

\subsection{Distribution Factors}

Suppose now that bargaining weights are continuous functions of a distribution factor $s$, that is, a variable that influences the bargaining positions without influencing either the individual preferences or the budget constraint (Browning and Chiappori, 1998). We assume that the social planner can influence this factor without additional cost. In practice, several such factors have been studied in the literature on couples, for instance divorce laws (see Chiappori et al., 2001) or the relative unearned income of the two spouses, as illustrated by the UK "wallet to purse" policy reform (Lundberg et al., 1997). Formally, the bargaining weights can be written as:

$$
\mu_{i}^{*}=m_{i}^{*}\left(\frac{Y}{\pi(\mathbf{p})}, s\right)
$$

and the household demand functions are: $\mathbf{x}=\mathbf{x}(\mathbf{p}, Y, s)$. The sharing rule can be manipulated according to:

$$
\frac{\partial \phi}{\partial s}=\frac{1}{\theta}\left(\frac{\partial \log \mu_{1}^{*}}{\partial s}-\frac{\partial \log \mu_{2}^{*}}{\partial s}\right)=M_{s}
$$

that is, the planner can increase member 1's share by increasing her relative bargaining weight directly. The first order condition (with respect to $s$ ) for the planner's problem is:

$$
\mu_{1} \frac{\partial v_{1}}{\partial \phi} \frac{\partial \phi}{\partial s}-\mu_{2} \frac{\partial v_{2}}{\partial \phi_{2}} \frac{\partial \phi}{\partial s}+\lambda \mathbf{t}^{\prime} \mathbf{R} \frac{\partial \phi}{\partial s}=0
$$

which simplifies into:

$$
\beta_{1}-\beta_{2}=-\theta \mathbf{t}^{\prime} \mathbf{R} M_{s}
$$

Assuming that $\pi(\mathbf{p})$ represents the true cost of living, the optimal rule becomes:

$$
\left(\mathbf{S}-\theta \mathbf{R} \mathbf{R}^{\prime}\right) \mathbf{t}=\bar{\alpha} \mathbf{x}-\gamma M_{s}
$$


where $\gamma=\theta \mathbf{t}^{\prime} \mathbf{R}$ is defined as previously. Quite surprisingly, the introduction of a distribution factor, although allowing the government to directly affect the intra-household distribution of resources, does not allow us to retrieve the traditional Ramsey rule. Indeed, variations in the distribution factor directly affect the household demand and, thereby, influence the revenue collected by the government. However, if all goods are taxed and if $\mathbf{p}^{\prime} \mathbf{x} \neq 0$, then a proportional tax will be optimal. This is completely analogous to the traditional Ramsey rule. To prove this, we suppose that $\tau$ is a proportional tax and then show that $\mathbf{t}=\tau \mathbf{p}$ solves the system of equation for $\bar{\alpha}=0$. In that case, the dead weight loss of the system of taxation is simply equal to zero.

Similarly, if both lump-sum tax and distribution factors are available, a sufficient solution corresponds to setting distribution factors so that dissonance disappears while lump-sum tax is in charge of revenue collection. Commodity tax is superfluous.

\section{Conclusion}

Income taxation or transfer to specific household members may not achieve its redistributive goal due to a well-known agency problem: it may be partly or totally neutralized by the intra-household redistribution process. The main message of our paper is that distortionary indirect taxation can circumvent the agency problem. That is, it is possible to operate redistribution in the household via "good" distortions of the price system. Simply stated, the planner should discourage less the consumption of those goods for which the slope of the Engel curves of the targeted person is the greater. Since children, men and women tend to consume different goods/services, there is ample scope for the implementation of redistributive policies of that type.

Future work should overcome some of the primary limitations of this contribution, including the facts that the analysis is in partial equilibrium and that we account only for private consumption (it is possible to extend the present model to public goods in 
the household as done in the collective model literature or very simply through Barten technology parameters, cf. Browning et al., 2006).

\section{Appendix}

Using expression (2), the pseudo-Slutsky matrix can be written as:

$$
\overline{\mathbf{S}}=\left(\frac{\partial \boldsymbol{\chi}_{1}}{\partial \mathbf{p}^{\prime}}+\frac{\partial \boldsymbol{\chi}_{1}}{\partial \phi_{1}} \frac{\partial \phi_{1}}{\partial \mathbf{p}^{\prime}}+\frac{\partial \boldsymbol{\chi}_{2}}{\partial \mathbf{p}^{\prime}}+\frac{\partial \boldsymbol{\chi}_{2}}{\partial \phi_{2}} \frac{\partial \phi_{2}}{\partial \mathbf{p}^{\prime}}\right)+\left(\frac{\partial \boldsymbol{\chi}_{1}}{\partial \phi_{1}} \frac{\partial \phi_{1}}{\partial Y}+\frac{\partial \boldsymbol{\chi}_{2}}{\partial \phi_{2}} \frac{\partial \phi_{2}}{\partial Y}\right) \mathbf{x}^{\prime}
$$

Simple manipulations give:

$$
\overline{\mathbf{S}}=\mathbf{S}+\left(\frac{\partial \boldsymbol{\chi}_{1}}{\partial \phi_{1}}-\frac{\partial \boldsymbol{\chi}_{2}}{\partial \phi_{2}}\right)\left(\frac{\partial \phi}{\partial \mathbf{p}^{\prime}}+\frac{\partial \phi}{\partial Y} \mathbf{x}^{\prime}-\mathbf{x}_{1}^{\prime}\right)
$$

where

$$
\mathbf{S}=\left(\frac{\partial \boldsymbol{\chi}_{1}}{\partial \mathbf{p}^{\prime}}+\frac{\partial \boldsymbol{\chi}_{2}}{\partial \mathbf{p}^{\prime}}+\frac{\partial \boldsymbol{\chi}_{2}}{\partial \phi_{2}} \mathbf{x}_{2}^{\prime}+\frac{\partial \boldsymbol{\chi}_{1}}{\partial \phi_{1}} \mathbf{x}_{1}^{\prime}\right)
$$

Using the decompositions of the derivatives of the sharing rule gives expression (7).

\section{References}

[1] Ahmad, E. and N. Stern (1984): "The Theory of Reform and Indian Indirect Taxes", Journal of Public Economics, 25, 259-298.

[2] Allgood, S. (2009): "The Collective Household, Household Production and Efficiency of Marginal Reforms", Journal of Public Economic Theory, 11 (5), 749-771

[3] Apps, P.F. and R. Rees (1988): "Taxation and the Household", Journal of Public Economics, 35, 355-369

[4] Apps, P.F. and R. Rees (1999): "On the taxation of trade within and between households", Journal of Public Economics 73(2), 241-63.

[5] Balestrino, A. (2004): "Revisiting The Equity-Efficiency Trade-off: Taxation with Non-cooperative Families", FinanzArchiv: Public Finance Analysis, 60, 515. 
[6] Bargain, O. and O. Donni (2011): "Targeting and Child Poverty", in revision for Social Choice and Welfare

[7] Becker, G.S. (1991): A Treatise on the Family, Enl. Edition, Cambridge University Press.

[8] Besley, T.J. and R. Kanbur (1988): "The Principles of Targeting", in: Lipton and ven der Gaag (eds), Including the Poor, World Bank.

[9] Brett, C. (1998): "Tax reform and collective family decision-making", Journal of Public Economics 70(3), 425-440

[10] Browning, M. and P.-A. Chiappori (1998): "Efficient Intra-household Allocations: A General Characterization and Empirical Tests", Econometrica, 66, 1241-1278.

[11] Browning, M., P.A. Chiappori and A. Lewbel (2006): "Estimating Consumption Economies of Scale, Adult Equivalence Scales, and Household Bargaining Power", Boston College Working Paper in Economics 588.

[12] Chiappori, P.-A. (1988): "Rational Household Labor Supply", Econometrica, 56, 63-89.

[13] Chiappori, P.-A. and O. Donni (2011): "Non-unitary Models of Household Behavior: A Survey". In: A. Molina (eds), Household Economic Behaviors, Berlin: Springer.

[14] Dauphin, A., A-R. El Lahga, B. Fortin and G. Lacroix (2011): "Are Children Decision-Makers Within the Household?", Economic Journal, forthcoming.

[15] Deaton, A. (1979): "Optimally Uniform Commodity Taxes", Economics Letters, 2, 357-361.

[16] Diamond, P.A. (1975): "A Many-Person Ramsey Rule", Journal of Public Economics, 4, 335-42. 
[17] Donni, O. (2006): "Collective Consumption and Welfare", Canadian Journal of Economics, 39, 124-144.

[18] Donni, O. (2003): "Collective household labor supply: Nonparticipation and income taxation", Journal of Public Economics 87(5-6), 1179-1198

[19] Gronau, R. (1988): "Consumption technology and the intrafamily distribution of resources - Adult equivalence scales reexamined". Journal of Political Economy, 96, $1183-1205$.

[20] Haddad, L. and R. Kanbur (1990): "How Serious is the Neglect of Intrahousehold Inequality?", Economic Journal, 100, 866-881.

[21] Kanbur, R. and L. Haddad (1994): "Are Better Off Household More Equal or Unequal?", Oxford Economic Papers, 46, 445-458.

[22] Kleven H.J., C.T. Kreiner and E. Saez (2009): "The optimal income taxation of couples", Econometrica, 77(2), 537-560.

[23] Lundberg S.J., R.A. Pollak and T.J. Wales (1997): “Do Husbands and Wives Pool Their Resources? Evidence from the U.K. Child Benefit", Journal of Human Resources, $32,3,463-480$.

[24] Makdissi P. and Q.Wodon (2002): "Consumption Dominance Curves: Testing for the Impact of Indirect Tax Reforms on Poverty" Economics Letters, 75, 227-235

[25] Mirrlees, J.A. (1976), "Optimal Tax Theory: A Synthesis", Journal of Public Economics, 6, 327-358.

[26] Pollak, R. (2005): "Family Bargaining and Taxes: A Prolegomenon to the Analysis of Joint Taxation", Taxation and the Family, CESifo Economic Studies, MIT Press.

[27] Samuelson P. (1956): "Social Indifference Curves ", Quarterly Journal of Economics, $70,1-22$. 